\section{Visualizar la mirada. Exploración artística a partir del seguimiento de ojos con imágenes en movimiento}

Alejandro Schianchi ${ }^{(1)}$, Laurence Bender ${ }^{(2)}$, Ignacio Guerra ${ }^{(3)}$ y Germán Ito ${ }^{(4)}$

Resumen: Se plantean una serie de reflexiones en torno a un proyecto de investigación-creación que explora la producción artística de visualizaciones a partir del registro experimental de la mirada frente a imágenes en movimiento. De esta manera, se relacionan elementos científico-tecnológicos de medición de la mirada con aspectos del lenguaje audiovisual y de la producción artística electrónica.

Las miradas se registran con un dispositivo de seguimiento ocular de alta resolución (eye tracker) aunque sus datos no son el objetivo final del presente análisis, sino parte fundamental de un proceso de creación de imágenes.

Las composiciones visuales creadas por software a partir de los recorridos oculares exhiben los aspectos activos y creativos involucrados en el proceso de mirar.

Una mirada, en una mirada, de una mirada. El creador de las imágenes aporta la primera, la persona que las contempla mientras se registran los movimientos de sus ojos, la segunda, y por último, la de los espectadores de las visualizaciones resultantes.

Al visualizar la mirada de cada espectador se rescata la experiencia singular ante esas imágenes. La relación única entre el espectador y las escenas observadas materializada en una exploración estética.

Palabras clave: Arte Electrónico - Cine - Visualización de datos - Mirada - Seguimiento de ojos.

[Resúmenes en inglés y portugués en la página 258]

(1) Magister en Tecnología y Estética de las Artes Electrónicas. Licenciado en Cinematografía y Técnico Electrónico en Computadoras. Docente de la Universidad Nacional de Tres de Febrero, Laboratorio de Arte Electrónico e Inteligencia Artificial. Sáenz Peña, Argentina (aschianchi@untref.edu.ar).

(2) Doctor en física por la Universidad de Buenos Aires y realizador cinematográfico egresado de la Universidad del Cine. Docente de la Universidad Nacional de Tres de Febrero, Laboratorio de Arte Electrónico e Inteligencia Artificial. Sáenz Peña, Argentina (lbender@ untref.edu.ar). 
${ }^{(3)}$ Licenciado en Artes Electrónicas. Docente de la Universidad Nacional de Tres de Febrero, Laboratorio de Arte Electrónico e Inteligencia Artificial. Sáenz Peña, Argentina (iguerra@ untref.edu.ar).

(4) Licenciado en Artes Electrónicas. Docente de la Universidad Nacional de Tres de Febrero, Laboratorio de Arte Electrónico e Inteligencia Artificial. Sáenz Peña, Argentina (gito@ untref.edu.ar).

\section{Introducción}

La posibilidad de registrar la mirada en el tiempo y con mucha precisión ante imágenes en movimiento abre nuevas perspectivas en torno a teorías de composición visual, teoría del cine, relación espectador-obra y la percepción visual en general. Inaugura, además, nuevos campos de saber específicos como la teoría fílmica cognitiva (Shimamura, 2013; Smith, 2013; Dwyer, Perkins, Redmond y Sita, 2018), que intenta comprender los procesos cognitivos al ver un film. Estableciendo relaciones entre las intenciones y decisiones del realizador con el campo de la psicología empírica y la neurociencia.

El proyecto $^{1}$ que aquí describimos puede ser objeto de análisis según esta teoría fílmica cognitiva al presentar la posibilidad de creación artística a partir de la mirada. Lo que da lugar a reflexionar sobre las implicancias del montaje, encuadre y lenguaje audiovisual en general. Tanto en la manera en que se perciben durante los experimentos, así como el funcionamiento de estos mismos elementos en las nuevas visualizaciones producidas. Por otro lado, de acuerdo a la creación artística algorítmica podría incluirse dentro del concepto de cine generativo (Grba, 2017) o de la estética de visualización de datos (Gaviria, 2008, Manovich, 2002).

Las secuencias utilizadas para los experimentos de observación del proyecto han sido seleccionadas por su interés narrativo, simbólico, histórico o visual, como la célebre escena de la ducha de Psicosis (1960) de Alfred Hitchcock, o la batalla del hielo de Alexander Nevsky (1938) de Sergei Eisenstein. En algunos casos se han elegido por la ausencia de una narrativa explícita y una composición deliberada para estimular una visión más libre, aunque siempre en torno a algún valor simbólico y/o visual. Por ejemplo, trabajando con registros de la Plaza de Mayo de la Ciudad de Buenos Aires, espacio público simbólico en la historia social y política de la Argentina.

La mirada aparece materializada en dos instancias sucesivas: la del realizador plasmada en las imágenes en movimiento a observar, y la del espectador de esas imágenes, registrada mediante el seguimiento de ojos (eye tracking). La relación entre ambas instancias sirve de base para la creación de nuevas imágenes. Con esos datos se producen composiciones visuales dinámicas que vinculan las imágenes originales y el registro de la mirada sobre las mismas. La "lectura" de la imagen en movimiento de distintos observadores son parte de la composición de imágenes (en movimiento o fijas) presentadas como una visualización 
de datos con fines artísticos, que a su vez serán objeto de una nueva mirada por parte del espectador de la obra.

La mirada activa y creadora define una nueva manera de observar las imágenes, dando lugar a que el espectador pueda verlas a través de la mirada de otro.

\section{La mirada}

"Solo vemos aquello que miramos. Y mirar es un acto de elección", dice John Berger (2016). Pero ¿por qué elegimos ver algo en lugar de otra cosa? ¿Qué hace que observemos un elemento antes que otro? A lo que el mismo autor propone: "lo que sabemos o lo que creemos afecta a cómo vemos las cosas." Cada mirada es única. La experiencia de cada sujeto con una obra también. La primera elección de qué y cómo mirar es la del que produce la imagen. Y como su reflejo, en segundo término, la del espectador ante ella.

Por lo tanto, si una imagen "incorpora un modo de ver", como puede ser la de un pintor, un fotógrafo, un cineasta, o un creador de imágenes cualquiera, "nuestra percepción o apreciación [...] depende de nuestro propio modo de ver" (Berger, 2016).

El proyecto articula estos dos modos de ver al vincular las imágenes seleccionadas para los experimentos (que incluyen una mirada), con las formas singulares de observación de cada individuo a través del recorrido único y visible de su mirada.

La visión humana es un proceso activo en el que el espectador continuamente busca la información visual relevante de una escena. La intencionalidad y finalidad de la misma es lo que define la mirada (Aumont, 1992).

Lo relevante para una persona puede ser diferente para otra, y en cualquiera de los casos los motivos por los que resulta más significativo pueden ser de diverso tipo. Aquello que Roland Barthes (2003) señaló como punctum en una fotografía y que viene a perturbar el studium, si lo analizamos más allá de cuestiones perceptivas fisiológicas. A pesar de que, tal como aclara Barthes, la "continua voracidad" del cine produce un tipo de relación con el espectador diferente a la de la fotografía.

En el campo del arte visual la disposición de la información relevante, así como las relaciones y distancias entre elementos, límites del cuadro, uso del color, etc., forman parte de los criterios de composición de una imagen. Si lo analizamos según el concepto de diagrama de Deleuze (2007), en el caso de la pintura hay un rol fundamental del pintor para dar lugar a un germen dentro del caos modulando la luz y el color. A lo que se puede sumar, siguiendo al mismo autor (Deleuze, 2005), lo que sucede en la imagen-movimiento con los conceptos de encuadre como sistema relativamente cerrado, el plano como el corte móvil de una duración, y el montaje en tanto composición y disposición de las imágenes movimiento.

Los criterios de composición pictórica que luego se extendieron (y redefinieron) en la fotografía y el cine responden a estilos personales y de épocas o a una función utilitaria para destacar el contenido de una imagen afectando, en definitiva, la mirada del espectador. La relación inevitable -dentro de las artes visuales- entre la percepción visual de quien mira y la obra ha sido objeto de elucubraciones. El creador de la imagen intuye la manera 
en la que su producción será asimilada visualmente a través de la organización de sus componentes, en particular si conoce la cultura visual del que la observará. Intentando, en ocasiones, conducir la mirada imaginada del espectador basándose en una sospecha. Esto es muy claro en el análisis de Eisenstein (1986) sobre la escena de Alexander Nevsky (1938). Los rostros, y dentro de ellos los ojos y la boca, son en general nuestro principal foco de atención que, como un reflejo de comunicación humana, busca captar rápidamente el sentido de la situación y la actitud de sus protagonistas. En el caso de las escenas dinámicas, como fragmentos de films, se suman otros elementos que dirigen la mirada como la inclusión sorpresiva de algún elemento en el cuadro o con un movimiento significativo, (Treuting, 2006). Cabe mencionar que la percepción también difiere en tanto simultaneidad de elementos en juego afectando la percepción general por comparación (Aumont, 1992). Estos reflejos son propios de nuestro sistema de percepción y por lo tanto endógenos, inconscientes.

Estos aspectos son analizados en trabajos de neurociencia y la psicología cognitiva bajo el término de saliencia visual (Smith, 2013), aunque el presente proyecto no pretende abordarlos explícitamente en las visualizaciones. Es decir, no se busca comprender los motivos por los que un espectador detuvo su atención en algún punto de la imagen, sino registrar simplemente su recorrido ocular como base para una posterior visualización.

Cabe mencionar que a diferencia de las representaciones habituales del registro de miradas sobre una imagen por medio de mapas de color o heatmaps (representando el promedio de múltiples miradas mediante color) las visualizaciones, en este caso, se definen con la intención de no perder el carácter singular de cada mirada individual.

\section{Registro de la mirada}

Los sistemas para el seguimiento de ojos tienen como antecedente las observaciones de Müller (1826a, 1826b) y Louis Émile Javal (1878, 1879), entre otros (Wade (2005, 2010), Torcal Cano (2012)). Javal, por ejemplo, hizo énfasis en que los movimientos oculares durante la lectura de textos no eran fluidos y lineales, sino que se componían de fijaciones y sacadas. Pequeñas detenciones sobre algunos puntos durante la lectura, intercalados con saltos rápidos. Estas investigaciones se realizaban con observaciones a simple vista o técnicas intrusivas, como la de Edmund Huey, los cuales no permitían mucha precisión. La oportunidad de registrar los movimientos oculares con mayor definición viene de la mano de implementaciones tecnológicas como el uso de cámaras que capten en soporte fílmico el reflejo de una luz en la córnea del ojo (Buswell, 1935) o un instrumento (photo-kymograph) que registre gráficamente las variaciones en el tiempo como el caso de Alfred Yarbus (1967).

En la actualidad, los eye trackers de alta resolución, como el que se utiliza en este proyecto, poseen una cámara especial para registrar la actividad ocular de ambos ojos mientras la persona visualiza imágenes de video. Utilizan técnicas ópticas de medición que localizan por contraste el centro de la pupila iluminando los ojos con luz infrarroja para lograr una reflexión en la córnea. El vector formado entre estos dos puntos permite calcular el cen- 
tro de atención de la mirada después de una simple calibración individual. Por lo tanto, resulta en una técnica sumamente precisa y poco invasiva para efectuar los experimentos. Los estudios mencionados son en relación a la contemplación de imágenes fijas. En cambio, el seguimiento ocular que propone el presente proyecto está realizado durante la contemplación de escenas dinámicas (imagen en movimiento).

\section{Producción artística con eye tracking}

Los dispositivos de seguimiento de ojos se utilizan en el campo de la neurociencia, psicología, medicina, desarrollos militares, diseño de interfaces y el análisis de estrategias visuales en marketing, entre otros. Como se puede apreciar en el film de Harun Farocki The Creators of Shopping Worlds (2001) el registro de la mirada sirve para determinar la ubicación más conveniente de productos en espacios de consumo como shoppings, supermercados y tiendas de compras. Sin embargo, no es frecuente encontrar esta tecnología en el campo de producción artística.

La distancia crítica sobre la construcción de las imágenes que plantea Farocki a lo largo de varios de sus films y en particular sobre la intermediación técnica que opera en ellas en función del poder militar, del control o el consumo es lo que lleva a Didi-Huberman (2013) a plantear que "todas las imágenes del mundo son el resultado de una manipulación" y que frente a cada imagen, lo que deberíamos preguntarnos es "cómo (nos) mira". En esta relación de interpelación que surge entre las imágenes y el observador es donde la producción artística electrónica puede aprovechar la información que le brinda el eye tracker.

El contacto visual y el vínculo que se construye entre la imagen y quien la observa es el eje de una de las primeras obras artísticas que incluyó un sistema de seguimiento ocular. De-Viewer (1992) de ART+COM consiste en una pantalla electrónica con la imagen de Muchacho sosteniendo un dibujo infantil (1515) del pintor italiano Giovanni Francesco Caroto que se ve modificada en tiempo real a medida que la mirada del espectador recorre la imagen.

Otro de los abordajes artísticos utilizando el eye tracker ha sido la exploración de la posibilidad de dibujar con la mirada. La serie Eye drawings (1992-94) de Jochem Hendricks son el resultado del registro en el tiempo de la posición de sus ojos frente a distintas imágenes u objetos.

En la Argentina, Mariano Sardón en colaboración con Mariano Sigman vienen trabajando desde el 2011 con diferentes obras que se basan en el seguimiento ocular. Como por ejemplo The Wall of Gazes (2011), una instalación que incluye varias pantallas donde retratos fotográficos se van revelando a medida que los datos de múltiples miradas sobre esa imagen producen trazos. 


\section{Visualización de datos como práctica artística}

En el proyecto actual el procesamiento de datos obtenidos por el eye tracker resulta en una visualización en forma de video o imágenes fijas. Estas visualizaciones se pueden conectar, por un lado, con una línea de producción artística conocida como info-aesthetics, data aesthetic, data visualization o visualization art (Manovich, 2002; Gaviria, 2008) y por otro, con la tradición del cine, el video y la fotografía.

El campo de la visualización de datos investiga la creación y el análisis de representaciones visuales de la información. Considerada por Lev Manovich (2002) como una de las nuevas formas culturales que son producidas gracias a la computación. Un conjunto de datos, que en principio se presentan como abstractos y sin estructura aparente, se transforma en una representación gráfica que pone de relieve y facilita la comprensión de las relaciones presentes entre esos datos. La visualización de datos es una herramienta habitual en la investigación científica y en otras disciplinas como el diseño gráfico, pero en este caso es explorado desde la experimentación artística.

En la primera década de este siglo muchos artistas han sumado la visualización de datos como un nuevo elemento de creación artística. Valiéndose de tecnologías electrónicas digitales se crean representaciones de datos con fines estéticos. El proyecto se ubica en una línea de creación afín, que indaga la mirada en una escena dinámica. El aspecto temporal propio del desarrollo de la escena y su relación con la temporalidad del recorrido de la mirada es el eje principal de experimentación y producción de visualizaciones.

En este sentido las visualizaciones de datos se conciben como procesos y materializaciones de exploración estética, vinculados íntimamente con las tecnologías involucradas para su realización. El proyecto apunta hacia una reflexión sobre la experiencia de la percepción visual en relación con el tiempo de una acción o narración. Además de la creación de representaciones que pongan de relieve diversas manifestaciones de esa experiencia.

\section{Composiciones con la mirada}

La serie de composiciones que se produjeron en el proyecto (consideradas work in progress) difiere de las visualizaciones de otras investigaciones de carácter científico que se proponen describir la percepción visual promedio ante diversas imágenes o tareas de ver. En cambio, en el proyecto en desarrollo, la intención es que cada una de las miradas involucradas en las composiciones mantenga su particularidad, mostrándolas individualmente en lugar de promediarlas.

Por otro lado, en la mayoría de las composiciones del proyecto se utilizan fragmentos de films con relevancia histórica o de prestigio para la Historia del Cine y del Arte. Los cuales poseen una riqueza visual y de montaje que potencian las observaciones y que se conectan, a su vez, con la corriente audiovisual denominada found footage (Wees, 1998; Weinrichter, 2009) en tanto práctica artística de resignificación y apropiación, al ser incluidas y procesadas en las visualizaciones generadas por software. 
Las estrategias de composición utilizadas son las de trazas, microencuadres y ampliaciones con la intención de remarcar la singularidad de la mirada y proponer nuevos mecanismos de encuadre y montaje generados algorítmicamente.

Las trazas se corresponden con una marca gráfica que da cuenta del recorrido de cada ojo. Se trata de una manera de visualizar la mirada que posee múltiples antecedentes (Buswell, 1935; Yarbus, 1967), aunque en este caso son trazas dinámicas que fluctúan a lo largo del tiempo. Los microencuadres son recortes de la imagen (en general rectangulares) centrados en el punto de atención de la mirada en determinado instante. Por último, las ampliaciones son zonas de la imagen que se agrandan a pantalla completa teniendo siempre como centro de la imagen el punto de atención del observador en ese momento.

\section{Alexander Nevsky - La batalla del hielo}
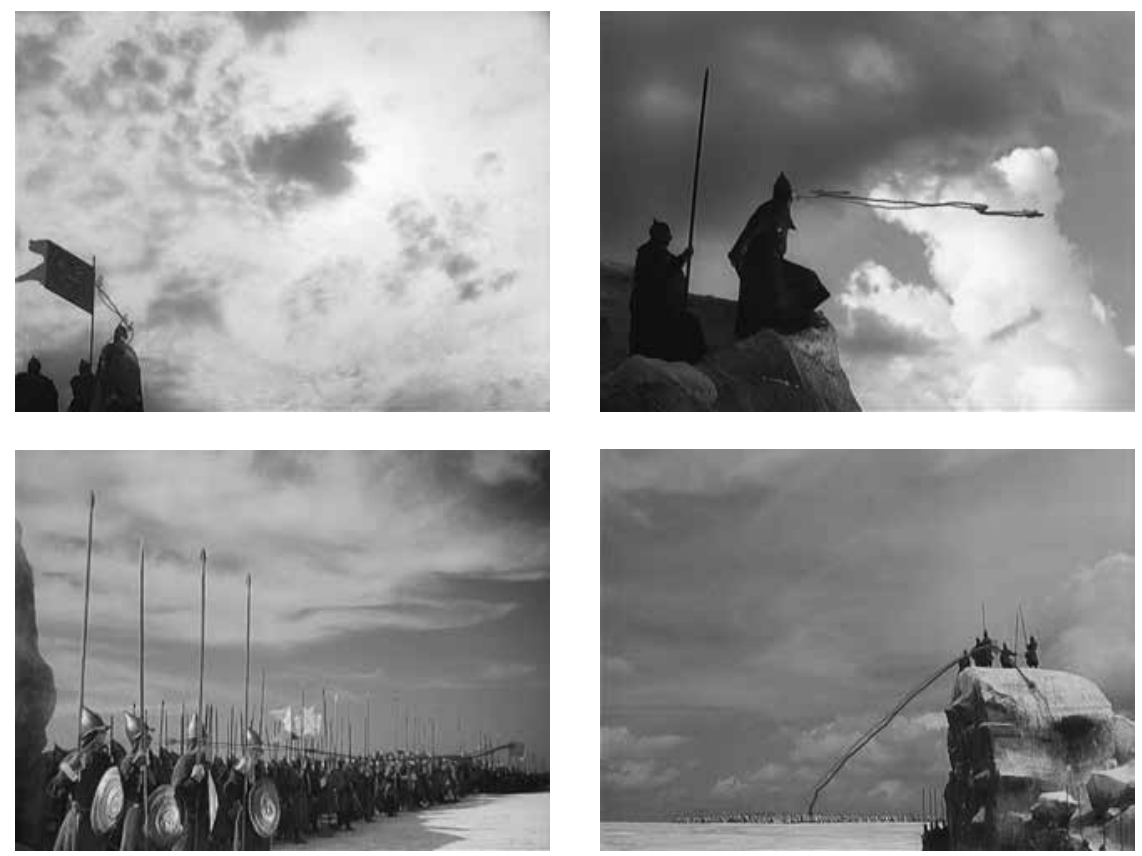

Figura 1. Fotogramas seleccionados de la composición a partir de la escena de Alexander Nevsky $(1938)^{2}$. 
La escena de La Batalla del Hielo del film Alexander Nevsky (1938) de Sergei Eisenstein resulta interesante para trabajar ya que el propio realizador escribió sobre la relación de los encuadres, el montaje y la música con el supuesto recorrido que tendría la mirada del espectador (Eisenstein, 1986). Por esta razón ya fue motivo de análisis en otras investigaciones similares, como la de Tim Smith (2014). Tanto en esa investigación como en los experimentos que se hicieron durante el presente proyecto se verificó que la hipótesis de Eisenstein en cuanto al recorrido de la mirada era, en la mayoría de la escena, acertada. A pesar de constatarse que la música no posee tanta incidencia sobre el trayecto de lectura de la imagen como Eisenstein imaginaba.

En este caso la mirada se visualiza sobre la escena con una línea azul y otra roja para cada uno de los ojos. Según el tipo de composición que denominamos trazas. El registro de la mirada se observa a medida que transcurre la escena logrando cautivar por la relación simple y explícita que se da entre ambas. Además, se puede notar claramente la actividad permanente de la mirada, su interés en los rostros (particularmente sobre los ojos y la boca) y cómo la composición de la imagen dirige su recorrido.

\section{Psicosis - La escena de la ducha}

Psicosis (1960) de Alfred Hitchcock probablemente sea una de las películas más resignificadas por artistas contemporáneos: Douglas Gordon, Jim Campbell, Palle Torsson, Martin Arnold, Steven Soderbergh y por supuesto Gus Van Sant, son algunos de ellos (Sprengler, 2014).
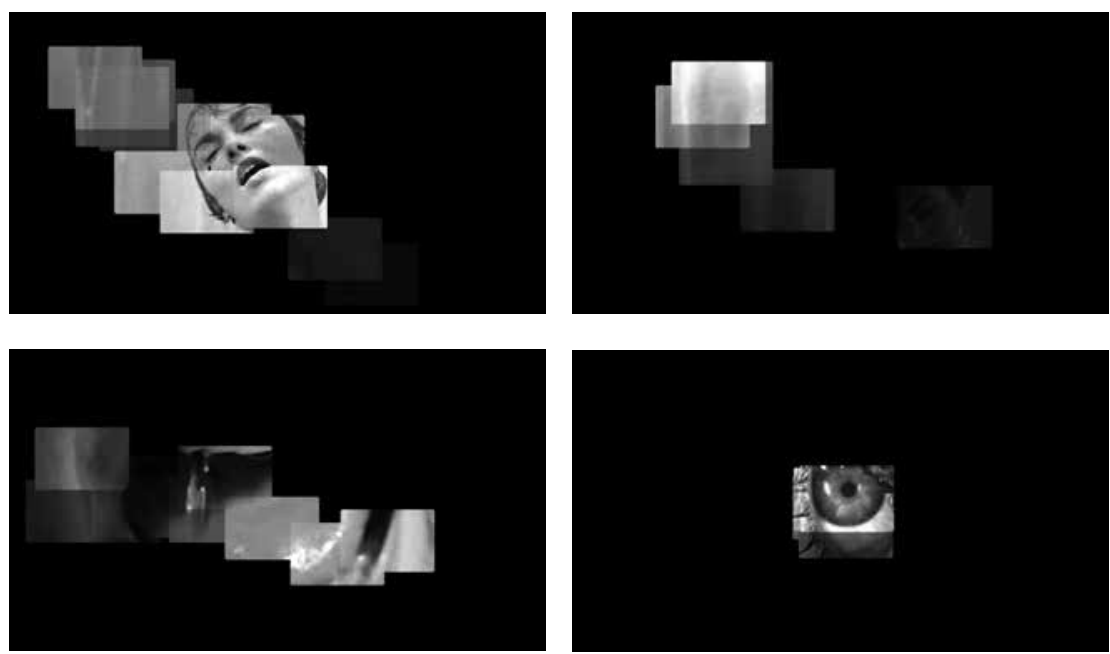

Figura 2. Fotogramas seleccionados de la composición a partir de la escena de Psicosis $(1960)^{3}$. 
A pesar de haber realizado diversos abordajes de composiciones sobre esta escena, mencionaremos simplemente uno de ellos a modo de ejemplo. Se trata del proceso de visualización que definimos como microencuadres y que se traduce en observar la escena a medida que surgen y desaparecen re-encuadres según las zonas donde el observador que participó del registro de su mirada estaba dirigiendo su atención (Figura 2).

Por momentos la mirada activa recorre diferentes áreas de la imagen haciendo visible la mayor parte de la escena original, pero frente a las acciones más rápidas o las imágenes más fuertes a nivel compositivo solo queda en la visualización un microencuadre central que acentúa la intensa relación entre el observador y la imagen.

\section{Plaza de Mayo (Ciudad de Buenos Aires) ${ }^{4}$}

Con el fin de experimentar con otro tipo de contenido audiovisual se realizó un registro en video de la Plaza de Mayo de la Ciudad de Buenos Aires sin ninguna intencionalidad narrativa explícita. Se trata de un plano general lo suficientemente amplio como para captar varios elementos en simultáneo (personas, autos, árboles) pero que permite, a su vez, identificar algunas situaciones y personajes en particular.

El encuadre es fijo y se trata de un único plano. Al no existir montaje de diferentes planos ni movimientos de cámara la atención visual puede desviarse libremente (free viewing) sin verse afectada directamente por un direccionamiento de la imagen original.

En esta visualización se propone trabajar con tres registros de observación correspondientes a diferentes personas y mostrarlos de manera simultánea. Cada uno de estos recorridos conserva su unicidad al asignársele un color primario de luz (rojo, azul o verde) mediante un filtro de procesamiento de imagen. El modo de composición de microencuadres en este caso funciona de manera aditiva cromática, dado que en las zonas donde se superponen se observa el resultado de la combinatoria de color correspondiente hasta llegar al blanco cuando se superponen las tres miradas.

\section{Conclusión}

Se presentan una serie de reflexiones a partir de exploraciones artísticas motivadas por la posibilidad de registrar la mirada con imágenes en movimiento mediante el dispositivo técnico eye-tracker. Las visualizaciones de datos con fines estéticos basados en la información de los experimentos de observación no solo pueden ser entendidas como producción artística, sino también como una manera diferente de dar cuenta del proceso dinámico y activo de la mirada. Las que habitualmente se hacen a partir del promedio de muchas miradas en heatmaps.

Algunas de estas reflexiones pueden enmarcarse dentro del campo de la teoría fílmica cognitiva al combinar elementos del lenguaje audiovisual como el encuadre, plano y montaje con aspectos de procesos algorítmicos generativos por software. Que se vinculan, a su vez, 
con prácticas de apropiación y resignificación del arte contemporáneo, cine generativo y arte electrónico.

Mediante los procedimientos de composición de trazas, microencuadres y ampliaciones se produce una manera de observar las imágenes a través de la mirada de otro.

En el proceso continuo de fragmentación y reconstrucción de la imagen original según el movimiento ocular registrado se da cuenta, de forma expresiva, del vínculo entre observador e imagen. Se trata de un montaje visual creado por un modo de ver. Una experiencia artística singular producida al hacer visible la mirada.

\section{Notas}

1. Información general sobre el proyecto disponible en http://mirada-tiempo-accion.sur www.com

2. Video completo de la composición en http://mirada-tiempo-accion.surwww.com/ composiciones.html

3. Video completo de la composición en http://mirada-tiempo-accion.surwww.com/ composiciones.html

4. Obra realizada en colaboración con Ignacio Vizcarra y exhibida en la Bienal de Arte Digital "The Wrong" de 2017. Disponible originalmente en http://www.displacements.net/ Consultado el (08/02/2018). Actualmente disponible en http://mirada-tiempo-accion. surwww.com/composiciones.html Consultado el (24/05/2020)

\section{Referencias Bibliográficas}

ART+COM Studios (s/f) De-viewer, disponible en https://artcom.de/en/project/de-viewer/ Consultado el (22/12/2017)

Aumont, J. (1992). La imagen. Barcelona: Paidós.

Barthes, R. (2003). La cámara lúcida. Nota sobre la fotografía. Buenos Aires: Paidós.

Berger, J. (2016). Modos de ver. Barcelona: Editorial Gustavo Gili.

Buswell, G. Th. (1935). How people look at pictures: a study of the psychology and perception in art. Chicago: The University of Chicago Press.

Grba, D. (2017). "Avoid Setup: Insights and Implications of Generative Cinema" en Journal of Science and Technology of the Arts, volumen 9 (número 1).

Deleuze, G. (2005). La imagen movimiento. Estudios sobre cine 1, Buenos Aires: Paidós.

Deleuze, G. (2007). Pintura. El concepto de diagrama, Buenos Aires: Cactus.

Dwyer, T.; Perkins, C.; Redmond, S. y Sita, J. (eds.) (2018). Seeing into Screens: Eye Tracking and the Moving Image. Bloomsbury Academic.

Eisenstein, S. (1986). El sentido del cine. México: Siglo Veintiuno.

Hendricks, J. (s/f). Eye drawings, disponible en http://www.medienkunstnetz.de/works/ augenzeichnungen/images/18/ Consultado el (22/12/2017). 
Javal, L. É. (1878). "Essai sur la physiologie de la lecture" en Annales d'Oculistique, volumen 80, pp. 240-274.

Javal, L. É. (1879). “Essai sur la physiologie de la lectura” en Annales d'Oculistique, volumen 82, pp. 242-253.

Manovich, L. (2002). Data Visualization as New Abstraction and Anti-Sublime. Disponible en http://manovich.net/index.php/projects/data-visualisation-as-new-abstraction -and-anti-sublime (recuperado el 05/05/2017)

Müller, J. (1826a). Zur vergleichenden Physiologie des Gesichtssinnes des Menschen und der Thiere, nebst einen Versuch über die Bewegung der Augen und über den menschlichen Blick, Leipzig: Cnobloch.

Müller, J. (1826b). Über die phantastischen Gesichtserscheinungen. Coblenz: Hölscher.

Ramirez Gaviria, A. (2008). "When Is Information Visualization Art?: Determining the Critical Criteria” en Leonardo, volumen 41 (número 5), pp. 479-482.

Sardón, M. (s/f). “The Wall of Gazes”, disponible en http://www.marianosardon.com.ar/ wall/wall_esp.htm Consultado el (22/12/2017)

Shimamura, A. P. (ed.) (2013). Psychocinematics. Exploring Cognition at the Movies. Nueva York: Oxford University Press.

Smith, T. J. (2013). "Watching you watch movies: using eye tracking to inform cognitive film theory" en Shimamura, A. (ed.) Psychocinematics. Exploring Cognition at the Movies. Nueva York: Oxford University Press.

Smith, T. J. (2014). “Audiovisual Correspondences in Sergei Eisenstein's Alexander Nevsky: A Case Study in Viewer Attention" en Ted Nannicelli, Paul Taberham (Eds.), Cognitive Media Theory. Nueva York: Routledge, pp. 85-105.

Sprengler, Ch. (2014). Hitchcock and contemporary art. Nueva York: Palgrave MacMillan.

Treuting, J. (2006). "Eye tracking and cinema: A study of film theory and visual perception" en Society of Motion Picture and Television Engineers, volumen 115, pp. 31-40.

Torcal Cano, M. G. (2012). Relación entre los movimientos sacádicos y la comprensión y velocidad lectora, disponible en http://reunir.unir.net/bitstream/handle/123456789/278/ Torcal_MariaGabriela.pdf Consultado el (16/04/2017).

Wade, N. (2010). "Pioneers of eye movement research" en Iperception, pp. 33-68, disponible en https:/www.ncbi.nlm.nih.gov/pmc/articles/PMC3563053/\#R86 Consultado el (16/04/2017).

Wade, N. \& Tatler, B. (2005). The Moving Tablet of the Eye: The Origins of Modern Eye Movement Research. Oxford University Press.

Wees, W. (1998). “Forma y sentido en las películas de Found Footage: una visión panorámica" en Archivos de la filmoteca: Revista de estudios históricos sobre la imagen, (número 30), pp. 124-135.

Weinrichter, A. (2009). Metraje encontrado. La apropiación en el cine documental y experimental. Navarra: Fondo de Publicaciones del Gobierno de Navarra.

Yarbus, A. L. (1967). Eye Movements and Vision, Nueva York: Plenum Press. 
Abstract: A series of reflections are presented concerning a research-creation project that explores the artistic production of visualizations based on gaze tracking experiments with moving images. In this way, scientific and technological elements of gaze measurement are related to aspects of audiovisual language and electronic art production.

The gazes are recorded with a high-resolution eye tracking device. The data obtained is a fundamental part of the imaging process, but not the subject of this analysis.

The visual compositions created by software from the gaze trajectories reveal the active and creative aspects involved in the process of seeing.

A gaze, into a gaze, of a gaze. The creator of the moving images provides the first, the person who watches these images while the movement of their eyes is recorded, the second, and finally, the spectators of the resulting visualizations.

By visualizing the gaze of individual viewers, a singular experience is revealed in the presence of the images. The unique relationship between the viewer and the observed scenes is materialized in an aesthetic exploration.

Keywords: Electronic Art - Cinema - Data visualization - Gaze - Eye tracking.

Resumo: Uma série de reflexões são propostas em torno de um projeto de pesquisa-criação que explora a produção artística de visualizações a partir do registro experimental do olhar diante de imagens em movimento. Dessa forma, os elementos científico-tecnológicos da medição do olhar estão relacionados a aspectos da linguagem audiovisual e da produção artística eletrônica.

Palavras chave: Arte eletrônica - filme - visualização de dados - olhar - rastreamento ocular.

[Las traducciones de los abstracts fueron supervisadas por el autor de cada artículo] 